\title{
A maioridade do Congresso Brasileiro de Atividade Física e Saúde (1997-2015)
}

É sabido que o interesse pela área de atividade física e saúde ultrapassa os limites da Educação Física. De fato, em diversos países, a Educação Física tem passado ao largo dos avanços nesta área, ficando com os pesquisadores da Saúde Pública e da Medicina a iniciativa e a liderança nas investigações e publicações mais relevantes sobre atividade física e saúde. No Brasil não tem sido assim.

Sabemos que os primeiros movimentos na direção de uma área preocupada com a associação da aptidão física e do exercício físico com a saúde das pessoas partiram de médicos com especialização esportiva, com destaque para o Professor Dr. Maurício Leal Rocha (UFRJ). De seu laboratório (LABOFISE) saíram diversos novos líderes para a academia, com formações distintas e incluindo alguns pioneiros da Educação Física. Universidades paulistas, gaúchas e do próprio Rio de Janeiro serviram de base para a expansão inicial da área, à época focadas na aptidão física e no treinamento esportivo. O LAFISCS (São Caetano do SUL), o laboratório da Educação Física na USP, o LAPEX da UFRGS, além do LABOFISE, foram os principais centros de estudo (laboratórios de fisiologia do exercício) focados nas ciências do esporte e que serviram de base para as primeiras investigações sobre aptidão física e saúde.

A partir dos anos 80, com o retorno dos primeiros doutores em Educação Física formados nos Estados Unidos e Alemanha, entramos numa nova era para a Educação Física Brasileira. Os programas de pós-graduação ganharam massa crítica para iniciar os cursos de doutorado, grupos de pesquisa pioneiros começaram a ser formados, mais e melhores eventos científicos foram propostos, publicações e periódicos científicos de melhor qualidade, além de intercâmbio com pesquisadores de centros mais avançados. Tais acontecimentos resultaram num círculo virtuoso que fez com que a Educação Física brasileira ganhasse momento para se tornar uma área acadêmica reconhecida. Hoje, este reconhecimento vai muito além das fronteiras do país.

Em 1991 criamos na UFSC o NuPAF (Núcleo de Pesquisa em Atividade Física e Saúde), seguindo a visão e o enfoque da Educação Física, mas agregando pesquisadores de outras áreas. Fomos, de certa forma, pioneiros na investigação da atividade física relacionada à saúde na perspectiva atual, muito influenciados por pesquisadores renomados como Steve Blair, Russel Pate e Charles Corbin, dos EUA, todos graduados em Educação Física. O trabalho no NuPAF criou a base para a área de Atividade Física Relacionada à Saúde no Mestrado em Educação Física da UFSC (1996) e no doutorado, em 2006. Ano após ano, novas lideranças foram formadas e novos grupos de pesquisa começaram a surgir, principalmente no sul e nordeste do Brasil, a partir da formação de mestres (depois doutores) em atividade física e saúde pela UFSC.

O Congresso Brasileiro de Atividade Física e Saúde (CBAFS) foi promovido pela primeira vez em 1997 pelo Núcleo de Pesquisa em Atividade Física e 
Saúde (NuPAF), em parceria com o Programa de Pós-Graduação em Educação Física da UFSC. O Congresso teve origem em evento de abrangência regional organizado na UFSC desde 1985 (Simpósio de Pesquisa em Educação Física).

Realizado sempre nos anos ímpares, o CBAFS teve suas primeiras edições (1 a 6) realizadas pelo NuPAF, em Florianópolis, com os seguintes temas: 1997 - Atividade Física, Aptidão Física e Saúde: Avanços Científicos e Perspectivas para a Educação Física; 1999 - Promoção de Estilos de Vida Ativos: da Criança ao Idoso; 2001 - Promoção de Atividade Física: da Pesquisa à Ação; 2003 - Atividade Física Saúde e Bem-estar: na Escola, na Empresa e na Comunidade; 2005 - Qualidade de Vida, Atividade Física e Lazer; e 2007 - Interdisciplinaridade na Promoção de Estilos de Vida Ativos. Renomados pesquisadores internacionais participaram do Congresso, fazendo crescer o interesse pela pesquisa e pela pós-graduação nesta área.

Em 2007, o crescimento da área fez amadurecer a ideia de criação de uma associação científica que congregasse pesquisadores, profissionais e estudantes interessados em temas relacionados à atividade física \& saúde. Durante o CBAFS naquele ano, em Florianópolis, criou-se a SOCIEDADE BRASILEIRA DE ATIVIDADE FÍSICA E SAÚDE, incorporando o Congresso Brasileiro de Atividade Física e Saúde por concessão do NuPAF/UFSC, assim como a REVISTA BRASILEIRA DE ATIVIDADE FÍSICA E SAÚDE, por nobre concessão de seu Editor, o Professor (hoje Doutor) Abdalah Achour Júnior, de Londrina.

A partir daí, viu-se um crescimento muito significativo nas publicações internacionais oriundas de pesquisadores brasileiros e o reconhecimento da área acadêmica referida como ATIVIDADE FÍSICA E SAÚDE, com destacada participação da Educação Física, perante outras áreas mais tradicionais em nosso país.

Em 2009, realizou-se o sétimo CBAFS, em Porto de Galinhas, por iniciativa do grupo da UPE, com o tema Atividade Física no Sistema Único de Saúde: da Atenção Básica às Ações Intersetoriais. Em 2011, o oitavo Congresso foi realizado em Gramado, por iniciativa dos colegas da UFPel (o tema foi Atividade Física e Saúde: da Concepção ao Envelhecimento) e, em 2013, Curitiba sediou a nona edição do CBAFS, com o tema Pessoas Ativas, Cidades Saudáveis, organizado pelo grupo da PUC/PR.

O Congresso Brasileiro de Atividade Física e Saúde (CBAFS) chega à sua décima edição, promovido pela Sociedade Brasileira de Atividade Física e Saúde (SBAFS) realizado em São Luís, no Maranhão, de 11 a 14 de novembro de 2015. Convidados Nacionais e Internacionais debaterão como as diferentes formas de desigualdade afetam a prática de atividade física e quais possíveis políticas públicas seriam capazes de impactar de forma positiva nos níveis de atividade física e saúde da população.

Minha vida profissional tem estreita relação com a história do Congresso Brasileiro de Atividade Física e Saúde, desde o sonho em realiza-lo, até a criação e a consolidação da Sociedade Brasileira de Atividade Física e Saúde. Mas não somente a minha vida profissional - foram muitos os colegas professores e alunos (principalmente da pós-graduação) que sonharam juntos e construíram o que hoje é o Congresso, a Sociedade e a própria Área de atividade física e saúde no Brasil. São muitos os nomes para aqui incluir (acabaria esquecendo alguns). Mas vocês sabem de quem estou falando. Obrigado!

Vamos nos encontrar em São Luís, de 11 a 14 de novembro de 2015! 